\title{
GRISCELLI SYNDROME AND ELECTROENCEPHALOGRAPHY PATTERN
}

\author{
Simone C. Vieira-Karuta', Izabella C. Bertoldo Silva', Nádia Aparecida P. Almeida ${ }^{2}$, \\ Lúcia de Noronha ${ }^{3}$, Mara Lúcia S.F. Santos ${ }^{4}$, Paulo B.N. Liberalesso ${ }^{4}$
}

In 1978 in France, Claude Griscelli and Michel Prunieras reported the cases of two girls who presented with silver gray hair, several episodes of fever, hepatosplenomegaly and pancytopenia. The combination of pigment dilution and recurrent infectious episodes raised the diagnosis of Chediak-Higashi syndrome. However, since giant granules were not seen in granulocytes, there were differences in light and electron microscopic examination of skin and hair and there were defects in cellular and humoral immunity, the authors proposed a new syndrome ${ }^{1}$. Since then, a little over than 60 cases of Griscelli syndrome (GS) have been reported in the medical literature in association with primary neurologic manifestations, with immunologic abnormalities or with silvery gray hair and hypopigmented skin as the only abnormality ${ }^{2,3}$. The physiopathology of GS is based on a limited transport of melanin taking to a melanossoma deposition in the melanocytes ${ }^{4}$. Many of these cases were found in multiple siblings and/or consanguineous parents, suggesting an autossomal recessive inheritance ${ }^{5,6}$. In 1997, Pastural et al. ${ }^{7}$ found a homozygous mutation of the gene encoding myosin VA protein (MYO5A) in a Turkish girl with Griscelli syndrome. In 2000, the same author presented evidence indicating the existence of a second locus associated with GS in the $15 q 21$ region, which is located less than $7,3 \mathrm{~cm}$ from the MYO5A gene, the RAB27A gene ${ }^{7}$. Currently, GS is classified into 3 types based on the genetic and molecular features. GS 1 is described as silvery gray hair, severe psychomotor delay and is related to MYO5A gene. GS 2 represents patients with silvery gray hair, immunologic abnormalities and variable neurologic defects and is related to RAB27A gene. Finally, GS 3 presents as hypopigmentation in the hair and skin without another findings and is related to a mutation in the $2 q 37.3$ chromossome ${ }^{4-7}$. The diagnosis is frequently made between 4 months and 7 years of age, with a 6-week-old patient being the youngest case reported $^{8}$. The main syndromes that should be considered in the differential diagnosis are Chediak-Higashi and Elejalde syndrome. This differentiation can be made through microscopic hair analysis and skin biopsy, and by the presence or absent of abnormalities in the granulocytes?.

This case report was approved by the ethics committee of Pequeno Principe Hospital and parental written informed consent was obtained for publication.

\section{CASE}

A 4-month-old male Brazilian infant, second child of consanguineous parents, with a healthy 6-year-old brother, was brought with complaints of recurrent chest infections. He was born by cesarean delivery at term and needed intensive care immediately due to a diaphragmatic hernia which was surgically corrected. Family history was negative for any relevant disease.

Examination identified diffuse depigmentation of skin, hair, eyebrows and eyelashes, microcephaly, nystagmus, red reflex of the eyes, global hypotonia with normal deep tendon reflexes (Figs 1 and 2). Abdominal examination revealed hepatosplenomegaly.

Hematological studies showed anemia, leucopenia with normal platelets count and the presence of $18 \%$ of atypical lymphocytes without clinical correlation. No Chediak-Higashi giant granules were noted in blood leucocytes or bone marrow cells. There were no abnormalities in renal and liver function. Serum immunoglobulins were normal except for a low IgG value. Serum reactions for herpes virus, cytomegalovirus, EpsteinBarr virus were negative. Abdominal ultrasound showed hepatosplenomegaly and the ophthalmologic exam revealed retinal pigmentary epithelium atrophy.

Although there was no history of seizures the electroencephalogram demonstrated disorganized background activity with frequent sharp wave discharges located in left posterior temporal and parietal regions and right posterior and medium temporal regions. Magnetic resonance of brain showed frontotemporal cortex atrophy more prominent in the right side. The light microscopic evaluation of the hair revealed parcial albinism.

\section{SÍNDROME DE GRISCELLI E PADRÃO ELETRENCEFALOGRÁFICO}

Pequeno Príncipe Hospital, Curitiba PR, Brazil: 'Medical Resident, Pediatrics Neurologic Department; ${ }^{2}$ Pediatric Dermatologic Department; ${ }^{3}$ Pathologic Department; ${ }^{4}$ Pediatric Neurologic Department.

Received 5 December 2007, received in final form 10 March 2008. Accepted 27 March 2008.

Dr. Paulo B.N. Liberalesso - Rua Benjamin Constant 90 / 73 - 80060-050 Curitiba PR - Brasil.E-mail: paulo.neuroped@uol.com.br 


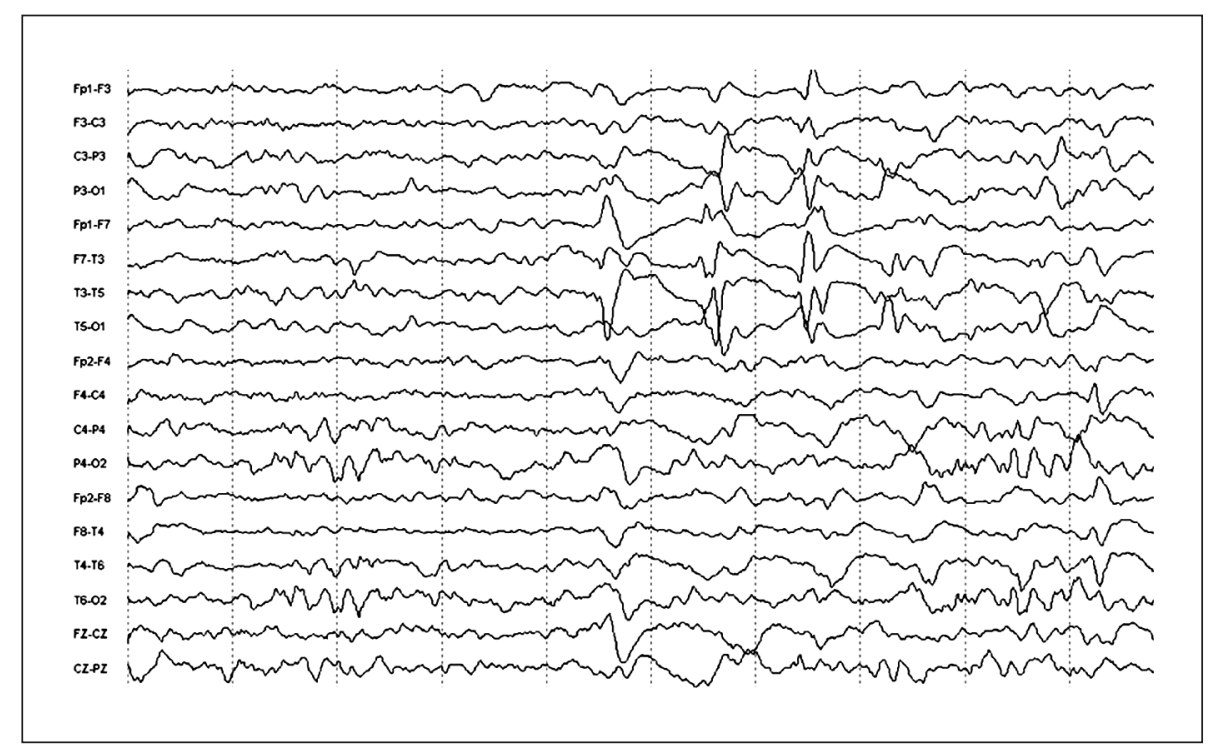

Fig 1. EEG with disorganized background activity and sharp wave discharges in left posterior temporal and parietal regions.

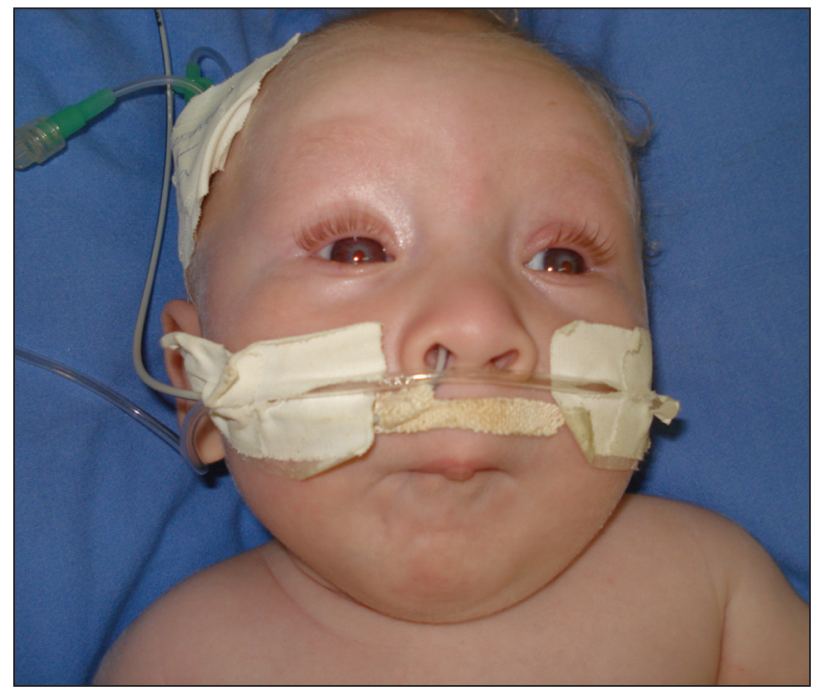

Fig 2. Pigmentary dilution of hair and skin. Red reflex of the eyes.

\section{DISCUSSION}

Griscelli syndrome is a rare and potencially fatal autossomal recessive disease. Pigment dilution of hair, skin, eyelashes and eyebrows, immunologic and neurologic abnormalities associated with hepatosplenomegaly and recurrent infections are the general features of $\mathrm{GS}^{8}$.

The variability of neurological manifestations is vast. Griscelli and Prunieras ${ }^{1}$, in the first description of the syndrome, did not described any neurologic manifestations. Latter, many authors reported the presence of seizures, intracranial hypertension, hemiparesis, facial palsy, hypotonia, psychomotor and language delay, progressive neurologic deterioration, cerebellar signs and spasticity ${ }^{4-12}$. According to Malhotra et al. ${ }^{3}$ severe neurologic abnor- malities are common in GS type 1 and may be absent in GS type 2. Klein et al." suggested that neurologic involvement in GS is secondary to diffuse lymphohistiocytic organ infiltration or to undocumented viral brain infection. This finding was not confirmed by any other study. No data about the prevalence of microcephaly was found.

A nonspecific EEG pattern is described in GS patients ${ }^{4,5}$. However, there are no studies specifically on the EEG patterns in these patients. The majority of the authors reported diffusely abnormal patterns ${ }^{4,11}$. The association between GS and brain malformations can generate changes nonspecific in EEG, as reported by Ashrafi et al. ${ }^{13}$ However, Alva-Moncayo et al. ${ }^{4}$ reported a specific EEG pattern with low amplitude, slow background activity and discharges in left temporal region. This report corroborates with our findings and suggests that an EEG pattern could be correlated with GS.

Neuroimaging findings consist of cerebral hypodense areas, ventricular dilation, hyperdense areas compatible with inflammatory changes, white matter changes and periventricular calcifications ${ }^{11}$. Cortical-subcortical atrophy and hypointensity in bilateral temporal white matter in MRI was documented by Alva-Moncayo et al. ${ }^{4}$.

Eye involvement is not common in GS. There is no report about eye abnormalities in GS type 1 and almost all cases of GS type 2 have normal ophthalmologic exam ${ }^{3}$. Mancini et al. ${ }^{5}$ cited one case of retinal hypopigmentation.

The systemic features include pigmentary dilution of hair, skin and less commonly of eyebrows and eyelashes, hepatosplenomegaly, limphadenopathy, recurrent infections as consequence of hypogamaglobulinemia, pancy- 
topenia and accelerated phases (virus associated hemophagocytic syndrome) $)^{11}$. The diagnosis of GS is established by the combination of clinical presentation, characteristic light and electron microscopic findings and the absence of giant granules in leukocytes ${ }^{8}$. Microscopic examination of hair reveals clusters of aggregated melanin pigment, accumulated mainly in the medullary area ${ }^{5}$.

The prognosis of the syndrome is very poor and the only effective treatment is the bone marrow transplantation ${ }^{2,10}$.

In spite of the fact that the mainly features of Griscelli syndrome are well known, more studies are needed in order to establish the real value of the EEG abnormalities in left temporal regions, determining a definitive electroencephalographic pattern.

\section{REFERENCES}

1. Griscelli C, Prunieras M. Pigment dilution and immunodeficiency: a new syndrome. Int J Dermatol 1978;17:788-791.

2. Haraldsson A, Weemaes CMR, Bakkeren JAJM, Happle R. Griscelli disease with cerebral involvement. Eur J Pediatr 1999;150:419-422.
3. Malhotra AK, Bhaskar G, Nanda M, Kabra M, Singh MK, Raman M. Griscelli syndrome. J Am Acad Dermatol 2006;55:337-340.

4. Alva-Moncayo E, Castro-Tarin M, Perez-Casillas R. Síndrome de Griscelli em México: descripción de um caso com manifestaciones neurológicas. Rev Neurol 2003;36:347-350.

5. Mancini AJ, Chan LS, Paller AS. Partial albinism with immunodeficiency: Griscelli syndrome. Report of a case and review of the literature. J Am Acad Dermatol 1998;38:295-300.

6. Arico M, Zecca M, Santoro N, et al. Successful treatment of Griscelli syndrome with unrelated donor allogeneic hematopoietic stem cell transplantation. Bone Marrow Transplant 2002;29:995-998.

7. Pastural E, Ersoy F, Yalman N, et al. Two genes are responsible for Griscelli Syndrome at the same 15q21 locus. Genomics 2000;63:299-306.

8. Kurugöl Z, Ozkinay F, Varadar F, et al. Griscelli syndrome: report a case and review of the literature. Pediatr Int 2001;43: 298-301.

9. Rath S, Jain V, Marwaha RK, Trehan A, Rajesh LS, Kumar V. Griscelli syndrome. Indian J Pediatr 2004;71:173-175.

10. Tezcan I, Sanal Ö, Ersoy F, et al. Successful bone marrow transplantation in a case of Griscelli disease which presented in accelerated phase with neurological involvement. Bone Marrow Transplant 1999;24:931-933.

11. Klein C, Phillippe N, Le Deist F, et al. Partial albinism with immunodeficiency (Griscelli syndrome). J Pediatr 1994;125:886-895.

12. Kumar TS, Ebenazar S, Moses PD. Griscelli syndrome. Indian J Dermatol 2006;51:269-271.

13. Ashrafi MR, Mohseni M, Yazdani S, et al. Bilateral basal ganglia involvement in a patient with Griscelli syndrome. Eur J Paediatr Neurol 2006;10:207-209. 